\title{
EDITORIAL
}

\section{New CMAJ policy on competing interests in guidelines}

\author{
Diane Kelsall MD MEd
}

Cite as: CMAJ 2019 April 1;191:E350-1. doi: 10.1503/cmaj.190316

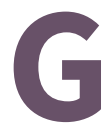

uidelines are powerful tools. They have the potential to change clinical practice and health policy - and, ultimately, the health of patients. But not always for the better. Undoubtedly, an inadequate methodology may result in a guideline with questionable clinical value. Biases, however, can creep into the development of any guideline, even those with robust methodologies. Financial and other relevant competing interests may affect a guideline's final recommendations, potentially leading to overdiagnosis and overtreatment of patients and higher health care costs. ${ }^{1}$ To address this, CMAJ is adopting a new policy on competing interests in clinical practice guidelines.

As of January 2020, CMAJ will be implementing the principles developed by the Guidelines International Network (GIN) regarding disclosure of competing interests and their management in clinical practice guidelines. ${ }^{2}$ The purpose of this new policy is to reduce the likelihood that recommendations of guidelines published in CMAJ are influenced by competing interests held by developers, funders and others involved in their production.

We all have competing interests, whether financial or indirect (e.g., personal, academic, religious or political), that can affect our work. ${ }^{3}$ Guidelines are particularly vulnerable to their effects, owing to the involvement of multiple stakeholders, and the many aspects of guideline development that occur over a lengthy time span. For guidelines, relevant competing interests are those that could influence the direction or strength of a recommendation. ${ }^{2}$

The 9 principles in the GIN guidance address the disclosure and management of competing interests throughout the guideline process. ${ }^{2}$ At the heart of these principles lies transparency, consistent with the International Committee of Medical Journal Editors (ICMJE) updated policy on competing interests, ${ }^{4}$ which CMAJ recently implemented. ${ }^{3}$

But GIN's guidance goes a step further in describing how to minimize the effects of competing interests on developing guideline recommendations. The definition of what constitutes a competing interest and its management should be determined before members are recruited for guideline development groups and must apply to all, regardless of discipline or stakeholders they represent. ${ }^{2}$
From the outset, guideline developers should make all possible efforts to avoid including participants in the guideline development group who have direct financial or relevant indirect competing interests. However, GIN recognizes that, for some guidelines, this may not be practical. In these situations, mitigation of risk of bias is essential. Steps include ensuring that participants with competing interests are a minority on guideline panels and that chairs (or their co-chairs) have no direct financial or relevant indirect competing interests. Importantly, no one on a guideline panel that is determining the direction or strength of a recommendation should have direct financial competing interests; moreover, members with these competing interests should be physically absent from these discussions. ${ }^{2}$

There should be an appropriate balance of opinion among those providing input. This may mean that expert advisers with relevant competing interests are, at times, permitted to participate in discussions on a given topic but should not be voting or nonvoting members of the guideline development group itself. ${ }^{2}$

To ensure transparency, CMAJ currently requires that guideline development groups disclose their individual members' competing interests on submission; these are collected on the ICMJE declaration form ${ }^{4}$ and included in the published guideline along with a description of how competing interests were managed during the guideline process. The guidance from GIN goes beyond this in recommending that members of guideline development groups with financial competing interests report specific monetary values; the guideline developer should also be clear about why it was necessary to include members with competing interests in producing the guideline. ${ }^{2}$

Developing a guideline can take years and, during that time, competing interests may arise that were not present at the start. All members of guideline development groups should disclose changes in their competing interests at each meeting and, for standing groups in particular, updates should be required at regular intervals. ${ }^{2}$

To aid in managing competing interests, GIN recommends that an oversight committee be struck that is responsible for developing and implementing the definition and rules related to competing interests. The scope of this committee's work should include addressing issues under dispute and aid the chair of the 
guideline development group in determining who is a voting or nonvoting member and who can participate in discussions as an expert adviser. ${ }^{2}$

CMAJ is interested in publishing high-quality guidelines that improve the health of patients. In selecting guidelines, we look for a strong methodology with a robust assessment of evidence using a tool like Grading of Recommendations Assessment, Development and Evaluation (GRADE; www.gradeworkinggroup. org), alignment with best practices such as those outlined in the updated version of the Appraisal of Guidelines for Research and Evaluation instrument (AGREE I; www.agreetrust.org) and, as of 2020 , adherence to the GIN principles ${ }^{2}$ for declaring and managing competing interests.

Developing a guideline is resource intensive and experts involved offer substantial time to the process. Appropriately managing competing interests during guideline development will help ensure that this effort was not in vain.

\section{References}

1. Jatoi I, Sah S. Clinical practice guidelines and the overuse of health care services: need for reform. CMAJ 2019;191:E297-8

2. Schünemann HJ, Al-Ansary LA, Forland F, et al. Board of Trustees of the Guidelines International Network. Guidelines International Network: principles for disclosure of interests and management of conflicts in guidelines. Ann Intern Med 2015;163:548-53.

3. Kelsall D. Updated CMAJ policy on undisclosed competing interests. CMAJ 2019;191:E116-7.

4. Recommendations for the conduct, reporting, editing, and publication of scholarly work in medical journals. International Committee of Medical Journal Editors; updated December 2018. Available: www.icmje.org/icmje-recommendations.pdf (accessed 2019 Mar. 18).

Competing interests: See www.cmaj.ca/site/misc/cmaj_staff.xhtml Affiliations: Editor-in-Chief (interim), CMAJ

Correspondence to: CMAJ editor, cmaj@cmajgroup.ca 